\title{
Proportional-integral and proportional-resonant based control strategy for PUC inverters
}

\author{
Samet Biricik \\ Technological University Dublin, sbiricik@eul.edu.tr \\ Hasan Komurcugil \\ Eastern Mediterranean University,Via Mersin 10, Turkey, hasan.komurcugil@emu.edu.tr
}

Follow this and additional works at: https://arrow.tudublin.ie/engscheleart

Part of the Electrical and Computer Engineering Commons

\section{Recommended Citation}

S. Biricik and H. Komurcugil, "Proportional-Integral and Proportional-Resonant Based Control Strategy for PUC Inverters," IECON 2018 - 44th Annual Conference of the IEEE Industrial Electronics Society, 2018, pp. 3369-3373, doi: 10.1109/IECON.2018.8591371.

This Conference Paper is brought to you for free and open access by the School of Electrical and Electronic Engineering at ARROW@TU Dublin. It has been accepted for inclusion in Conference papers by an authorized administrator of ARROW@TU Dublin. For more information, please contact arrow.admin@tudublin.ie, aisling.coyne@tudublin.ie,gerard.connolly@tudublin.ie.

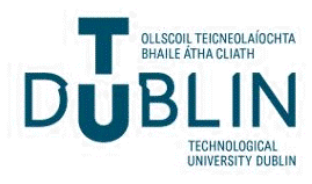




\title{
Proportional-Integral and Proportional-Resonant Based Control Strategy for PUC Inverters
}

\author{
Samet Biricik ${ }^{1,2}$ and Hasan Komurcugil ${ }^{3}$ \\ ${ }^{1}$ Department of Electrical and Electronics Eng., European University of Lefke, Lefke, Northern Cyprus TR-10 Mersin, Turkey \\ ${ }^{2}$ School of Electrical \& Electronic Engineering, Dublin Institute of Technology (DIT), Dublin, Ireland. \\ ${ }^{3}$ Department of Computer Engineering, Eastern Mediterranean University, Famagusta, Via Mersin 10, Turkey \\ sbiricik@eul.edu.tr, hasan.komurcugil@emu.edu.tr
}

\begin{abstract}
In this paper, a proportional-integral (PI) and proportional-resonant (PR) based control strategy is proposed for packed-U-cell (PUC) inverters. In the conventional PI-PI based control strategy, while the first PI regulates the DC capacitor voltage, the second PI regulates the AC load current. However, it is shown that the second PI cannot guarantee zero tracking error in the load current. The main reason of this comes from the fact that PI controllers are not able to achieve zero tracking error for the AC signals. Also, in an attempt to reduce the tracking error by tuning PI gains distorts the load current. In this study, a PI-PR based control strategy is obtained by replacing the second PI by a PR controller. The performances of both PI-PI and PI-PR control methods have been compared. It is shown that the load current to tracks its reference in all circumstances provided that the inverter current reference is generated accurately. Computer simulations are conducted to show the steady-state and dynamic performances of both control methods.
\end{abstract}

Keywords-Packed-U-cell (PUC) inverter, proportionalintegral control (PI), proportional-resonant (PR) control.

\section{INTRODUCTION}

Power converters such as uninterruptible power supplies, off-grid inverters and on-grid inverters have come a long way through developmental stages and made their applications almost inevitable due to the need of power efficiency and performance requirements. The traditional converters like the full-bridge or half-bridge topologies are the most preferred low-cost power structures for the industry. When traditional converters are used to inject the energy from a dc source to ac grid, the harmonic components should be considered at the filter side especially at the high-power applications. In order to reduce voltage stresses and distortions, multilevel converters like neutral point clamped (NPC) [1], [2] and flying capacitor (FC) [3], [4] converters are proposed. The main advantage of multilevel converters is that they generate voltage and current waveforms with low harmonic distortion. However, their implementation is complicated and costly due to the high number of switches, capacitors and diodes employed in a typical n-level converter.

Packed-U-Cell (PUC) converter is proposed as an alternative to the NPC and FC converters [5]. Detailed comparison of the PUC converter with the well-known topologies is presented in [6]. The 7-level PUC converter topology has six switches and two dc-links. For inverter applications, a battery source should be connected to the first dc-link and a capacitor is used for the second dc-link. In this topology, the PUC inverter operates successfully if the dc capacitor voltage is controlled. In" recent literature, increasing attention has been paid to the PUC converters due to the various advantages over the traditional dc-ac converters. However, the PUC based drivers or inverters are not yet ready for mass production. This is mainly because of the difficulties in the dc-link capacitor voltage control and switching issue.

To solve the above-mentioned limitations of the PUC based converter topologies various methods have been investigated in the last ten years. When the PUC is operated as an inverter, the objectives of the control strategies include the regulation of dc capacitor voltage and load current. Various control strategies such as hysteresis control [6], voltage balancing control [7], cascaded nonlinear control [8], finite-control-set model predictive control [9], model predictive control [10], [11], multi-objective model predictive control [12] and sensor-less based control [13] are proposed to achieve these objectives. In these works, the control approach is based on using two proportional-integral (PI) controllers. While the first PI is used to control the capacitor voltage, the second one is used to control the load current. The first PI controller generates the amplitude of the reference load current by processing the capacitor voltage error. On the other hand, the second PI controller produces the sinusoidal modulating signal by processing the load current error. The main drawback of these methods is the inability of the second PI in achieving zero tracking error in the load current. Also, in an attempt to reduce the tracking error by tuning PI gains distorts the load current.

In this paper, a PI-proportional resonant (PI-PR) based control strategy is proposed for PUC inverters. It is well known that PR controllers exhibit excellent performance in tracking an AC reference signal. Motivated from this fact, the conventional PI-PI based control is modified by replacing the second PI with a PR controller. The performances of both PI-PI and PI-PR control methods have been compared. The main advantage of the proposed PI-PR based control strategy is that the load current tracks its reference in all circumstances provided that the inverter current reference is generated accurately. Computer simulations are conducted to show the steady-state and dynamic performances of both control methods. 


\section{SEVEN-LEVEL PUC INVERTER MODELING}

The single-phase 7-level PUC inverter containing six switches, one isolated dc source and one capacitor is shown in Fig. 1. Each cell is constituted by the pair of $\left(Q_{i}, \bar{Q}_{i}\right)$ and a capacitor. The operation of the switches is defined as

$$
Q_{i}=\left\{\begin{array}{ll}
0, & \text { if } Q_{i} \text { is OFF } \\
1, & \text { if } Q_{i} \text { is ON }
\end{array} \quad, \quad i=1,2,3\right.
$$

It should be noted that $Q_{i}$ and $\bar{Q}_{i}$ work complementarily. This means that each pair of $\left(Q_{i}, \bar{Q}_{i}\right)$ cannot conduct simultaneously. Since each cell has two switches, the PUC inverter with three cells can produce an output voltage with seven levels. The switch states and output voltage levels are depicted in Table I.

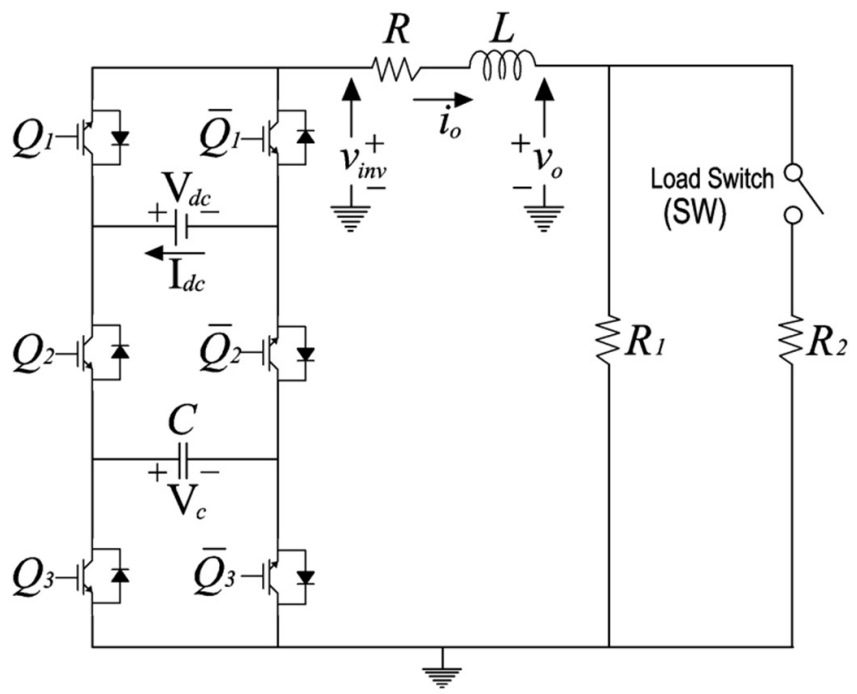

Fig. 1. Seven-level single-phase PUC inverter.

TABLE I

SWITCHING STATES AND SEVEN LEVELS GENERATED By PUC INVERTER

\begin{tabular}{|c|c|c|c|}
\hline$\left(Q_{1}, \bar{Q}_{1}\right)$ & $\left(Q_{2}, \bar{Q}_{2}\right)$ & $\left(Q_{3}, \bar{Q}_{3}\right)$ & $\mathbf{V}_{\text {inv }}$ \\
\hline 1,0 & 0,1 & 0,1 & $\mathrm{~V}_{\mathrm{dc}}$ \\
\hline 1,0 & 0,1 & 1,0 & $\mathrm{~V}_{\mathrm{dc}}-\mathrm{V}_{\mathrm{c}}$ \\
\hline 1,0 & 1,0 & 0,1 & $\mathrm{~V}_{\mathrm{c}}$ \\
\hline 1,0 & 1,0 & 1,0 & 0 \\
\hline 0,1 & 0,1 & 0,1 & 0 \\
\hline 0,1 & 0,1 & 1,0 & $-\mathrm{V}_{\mathrm{c}}$ \\
\hline 0,1 & 1,0 & 0,1 & $\mathrm{~V}_{\mathrm{c}}-\mathrm{V}_{\mathrm{dc}}$ \\
\hline 0,1 & 1,0 & 1,0 & $-\mathrm{V}_{\mathrm{dc}}$ \\
\hline
\end{tabular}

In order to obtain seven output voltage levels, it is required to have $V_{d c}=3 V_{c}$. In Table I, replacing $V_{d c}$ by $V_{d c}=3 V_{c}$ results in 0 , $\pm V_{c}, \pm 2 V_{c}$ and $\pm 3 V_{c}$. In order to obtain these levels, the capacitor voltage $\left(V_{c}\right)$ should be regulated at $V_{d c} / 3$. Clearly, two of the states generate zero voltage at the inverter output. On the other hand, it is obvious that the maximum value of inverter output voltage $\left(v_{i n v}\right)$ cannot exceed the dc source voltage $\left(V_{d c}\right)$. The differential equations describing the operation of the inverter can be written as

$$
\begin{aligned}
& C \frac{d V_{c}}{d t}=\left(Q_{3}-Q_{2}\right) i_{o} \\
& L \frac{d i_{o}}{d t}+R i_{o}=v_{i n v}-v_{o}
\end{aligned}
$$$$
\text { where } v_{i n v}=\left(Q_{1}-Q_{2}\right) V_{d c}+\left(Q_{2}-Q_{3}\right) V_{c} \text {. }
$$

\section{CONVENTIONAL PI-PI BASED CONTROL STRATEGY}

The objectives of the control strategies devised for PUC inverter include the regulation of dc capacitor voltage $\left(V_{c}\right)$ and load current $\left(i_{o}\right)$. Various control strategies such as hysteresis control [6], voltage balancing control [7], cascaded nonlinear control [8], and finite-control-set model predictive control [9] are proposed to achieve these objectives. In these control methods, the capacitor voltage is regulated by using a proportional-integral (PI) controller which processes the capacitor voltage error and produces the amplitude of the reference load current as follows

$$
I_{o}^{*}=K_{p 1}\left(V_{c}^{*}-V_{c}\right)+K_{i 1} \int\left(V_{c}^{*}-V_{c}\right) d t
$$

where $I_{o}^{*}$ denotes the amplitude of reference load current $i_{o}^{*}$. In the steady-state, $I_{o}^{*}$ converges to a value which can be computed from power balance equation as follows

$$
I_{o}^{*}=\frac{2 I_{d c} V_{d c}}{V_{o}}
$$

In (5), $V_{o}$ denotes the amplitude of $v_{o}$. The reference load current can be obtained by multiplying $I_{o}^{*}$ with the unit sine wave as follows

$$
i_{o}^{*}=I_{o}^{*} \sin \omega t
$$

In order to regulate the load current $i_{o}$, a second PI controller is used to produce the sinusoidal modulating signal as follows

$$
m=K_{p 2}\left(i_{o}^{*}-i_{o}\right)+K_{i 2} \int\left(i_{o}^{*}-i_{o}\right) d t
$$

The modulating signal is compared with the level shifted triangular waveforms to produce the pulse width modulation (PWM) signals shown in Table I. The block diagram of this control method is shown in Fig. 2.

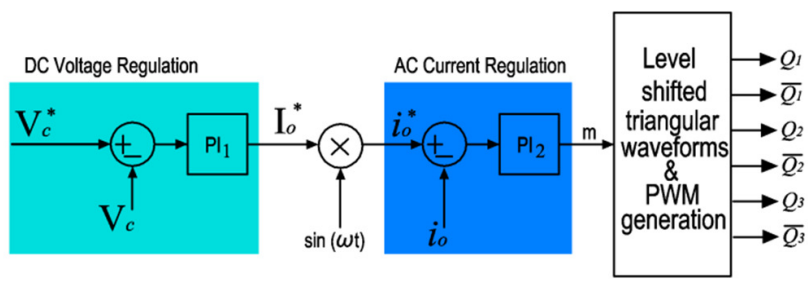

Fig. 2. Block diagram of conventional control method using two PI controllers.

It is well known that PI controllers exhibit good dynamic and steady-state performance for dc quantities. However, their 
performance in the regulation of sinusoidal quantities, such as load current $i_{o}$, is not satisfactory.

\section{PI-PR BASED CONTROL STRATEGY}

Due to the excellent performance in tracking an $\mathrm{AC}$ reference signal, the proportional-resonant $(\mathrm{PR})$ controllers are widely used in the regulation of AC variables. In this study, the modulation signal shown in (7) is proposed to be generated by a proportional-resonant $(\mathrm{PR})$ controller whose transfer function is given by

$$
G(s)=K_{p r}+\frac{2 K_{r} \omega_{c} s}{s^{2}+2 \omega_{c} s+\omega^{2}}
$$

where $\omega_{c}$ is the cut-off frequency, $\omega$ is the resonant frequency, $K_{p r}$ and $K_{r}$ are proportional and resonant gains, respectively. The operation of PR controller can be described by the internal model principle proposed in [14]. The input applied to the PR controller is the load current error $\left(i_{o}^{*}-i_{o}\right)$. According to this principle, if $\omega$ is set to the frequency of reference load current, which is $100 \pi \mathrm{rad} / \mathrm{s}$ in this study, the PR controller generates a sharp peak at $\omega=100 \pi \mathrm{rad} / \mathrm{s}$ resulting in zero steady-state error in $\left(i_{o}^{*}-i_{o}\right)$. In other words, one can say that $i_{o}$ tracks its reference $i_{o}^{*}$ without any error. It is worth noting that $G(s)$ in (8) represents a non-ideal transfer function used in practical applications. The ideal transfer function which does not involve $\omega_{c}$ and $2 \omega_{c} s$ terms in the nominator and denominator, respectively, cannot be realized in practice. The magnitude and phase responses of ideal and non-ideal PR are shown in Fig. 3. It is evident that the gain of magnitude response at $\omega=100 \pi \mathrm{rad} / \mathrm{s}$ obtained by non-ideal PR has been reduced considerably. The desired dynamic and steady-state responses of the inverter can be obtained by tuning $K_{p r}$ and $K_{r}$.

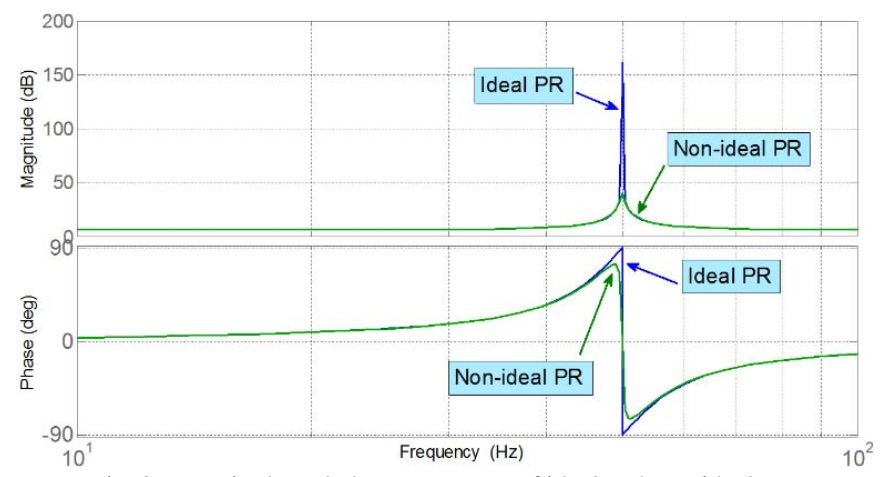

Fig. 3. Magnitude and phase responses of ideal and non-ideal PR.

\section{Simulation Results}

The effectiveness and correct operation of the proposed control strategy has been verified by simulations using Matlab/Simulink. The system and control parameters used in the simulation studies are given in Table II.

TABLE II

SYSTEM AND CONTROL PARAMETERS

\begin{tabular}{|l|c|}
\hline \multicolumn{1}{|c|}{ Description and Symbol } & Value \\
\hline DC source voltage, $V_{d c}$ & $150 \mathrm{~V}$ \\
\hline Capacitance, $C$ & $2000 \mu \mathrm{F}$ \\
\hline Filter inductance, $L$ & $5 \mathrm{mH}$ \\
\hline Resistance of inductor, $R$ & $0.5 \Omega$ \\
\hline Load resistance, $R_{1}$ and $R_{2}$ & $10 \Omega, 10 \Omega$ \\
\hline Switching frequency, $f_{s}$ & $8 \mathrm{kHz}$ \\
\hline Sampling time, $T_{s}$ & $30 \mu \mathrm{s}$ \\
\hline Reference capacitor voltage, $V_{c}^{*}$ & $30 \mathrm{~V}$ \\
\hline Gains of first PI, $K_{p 1}$ and $K_{i 1}$ & $0.25,10$ \\
\hline Gains of second PI, $K_{p 2}$ and & $1.5,50$ \\
$K_{i 2}$ & \\
\hline Gains of PR, $K_{p r}$ and $K_{r}$ & $1.79,700$ \\
\hline Cut-off frequency, $\omega_{c}$ & $1 \mathrm{rad} / \mathrm{s}$ \\
\hline
\end{tabular}

The block diagram of seven-level single-phase PUC inverter with the proposed PI-PR based control strategy is shown in Fig. 4.

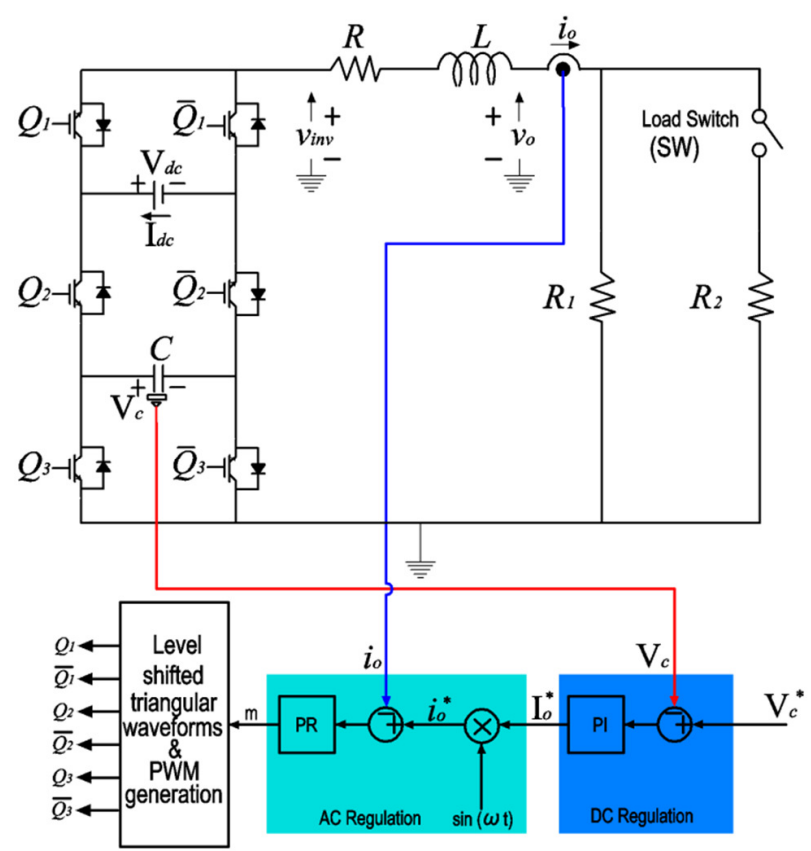

Fig. 4. Block diagram of seven-level single-phase PUC inverter with the proposed PI-PR based control. 
Fig. 5 shows the steady-state responses of $i_{o}, i_{o}^{*}$ and $m$ obtained by the conventional PI-PI based control strategy under $R_{1}$. It can be seen from Fig. 5(a) that $i_{o}$ cannot track $i_{o}^{*}$ with zero steady-state error. The main reason of this comes from the insufficient performance of the second PI controller in regulating the AC load current. Also, the total harmonic distortion (THD) of $i_{o}$ is computed to be $3.96 \%$. The modulating signal $(m)$ is shown in Fig. 5(b).

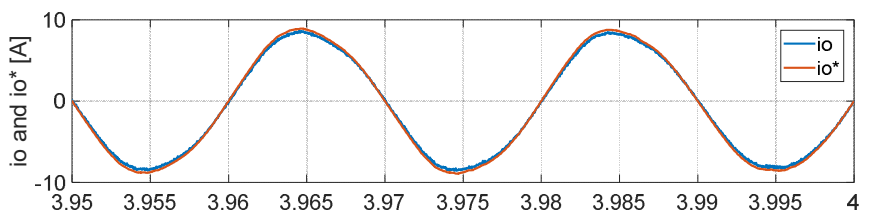

(a)

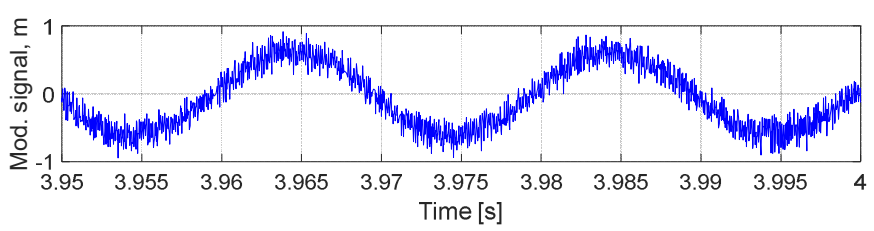

(b)

Fig. 5. Steady-state responses of $i_{o}, i_{o}^{*}$ and $m$ obtained by the conventional PI-PI based control under $R_{1}$. (a) $i_{o}$ and $i_{o}^{*}$ (b) $m$.

Fig. 6 shows the dynamic responses of $\mathrm{AC}$ and $\mathrm{DC}$ variables obtained by the conventional PI-PI based control strategy when $R_{2}$ is disconnected suddenly at $\mathrm{t}=2 \mathrm{~s}$. It is obvious from Fig. 6(a) that $i_{o}$ tracks its reference whose amplitude is generated by the first PI controller. It can be seen from Fig. 6(b) that the capacitor voltage tracks its reference successfully. The inverter output voltage has seven levels ($150 \mathrm{~V},-100 \mathrm{~V},-50 \mathrm{~V}, 0 \mathrm{~V},+50 \mathrm{~V},+100 \mathrm{~V}$, and $+150 \mathrm{~V})$ as shown in Fig. 6(c).

Fig. 7 shows the steady-state responses of $i_{o}, i_{o}^{*}$ and $m$ obtained by the proposed PI-PR based control strategy under $R_{1}$. It can be seen from Fig. 7(a) that $i_{o}$ tracks $i_{o}^{*}$ with zero steady-state error. The THD of $i_{o}$ is computed to be $2.98 \%$. The modulating signal $(m)$ is shown in Fig. 7(b).

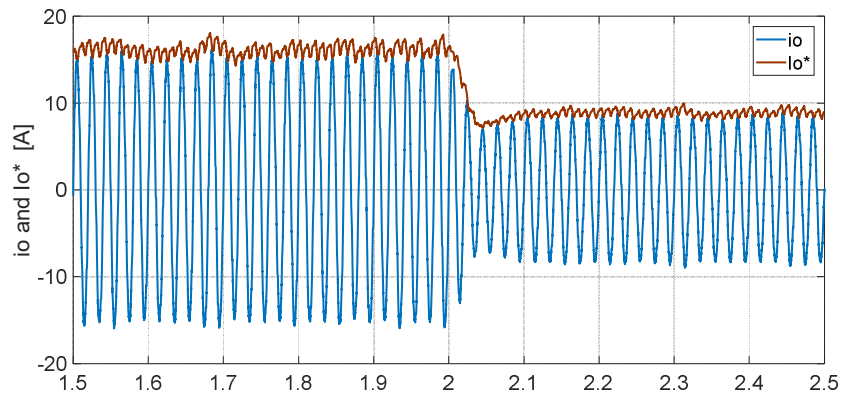

(a)

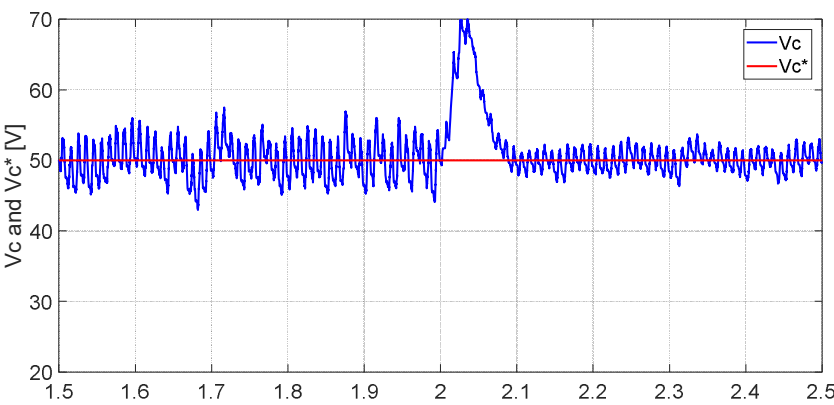

(b)

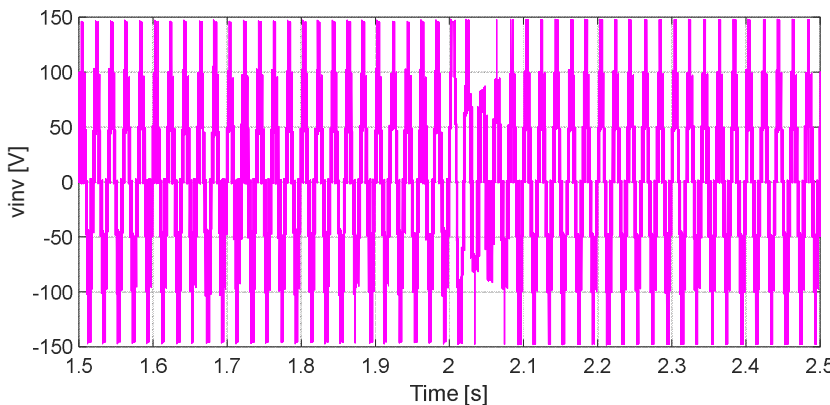

(c)

Fig. 6. Dynamic responses of $\mathrm{AC}$ and $\mathrm{DC}$ variables obtained by the conventional PI-PI based control when $R_{2}$ is disconnected suddenly at $\mathrm{t}=2 \mathrm{~s}$. (a) $i_{o}$ and $I_{o}^{*}$ (b) $V_{c}$ and $V_{c}^{*}$, (c) $v_{i n v}$.

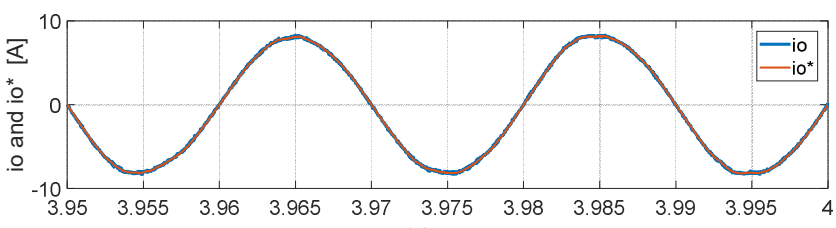

(a)

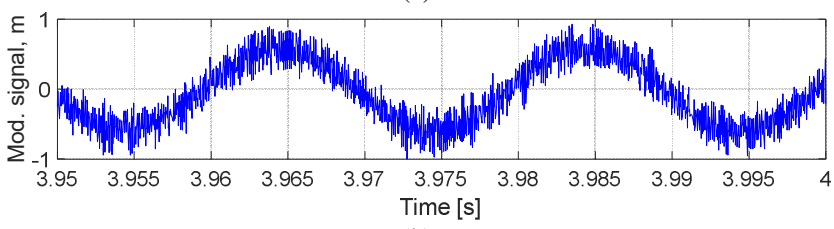

(b)

Fig. 7. Steady-state responses of $i_{o}, i_{o}^{*}$ and $m$ obtained by the proposed PI-PR based control under $R_{1}$ : (a) $i_{o}$ and $i_{o}^{*}$ (b) $m$.

Comparing Figs. 5 and 7, one can see that the proposed PIPR based control strategy performs better than the conventional PI-PI based control strategy in terms of load current's THD and tracking capability.

Fig. 8 shows the dynamic responses of AC and DC variables obtained by the proposed PI-PR based control strategy when $R_{2}$ is disconnected suddenly at $\mathrm{t}=2 \mathrm{~s}$. It is obvious from Fig. 8(a) that $i_{o}$ tracks its reference whose amplitude is generated by the first PI controller. The capacitor 
voltage tracks its reference successfully as clearly shown in Fig. 8(b). The inverter output voltage $\left(v_{i n v}\right)$ displayed in Fig. 8(c) has seven levels as mentioned in the Introduction Comparing, Figs. 6 and 8, one can see that the dynamic performances of both methods are very close to each other.

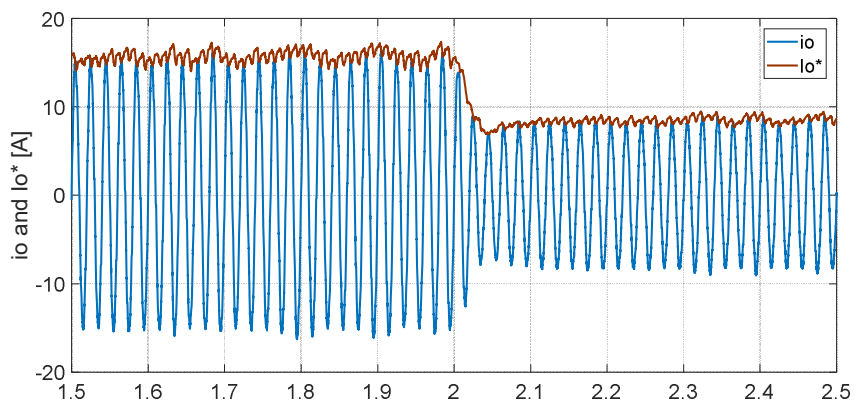

(a)

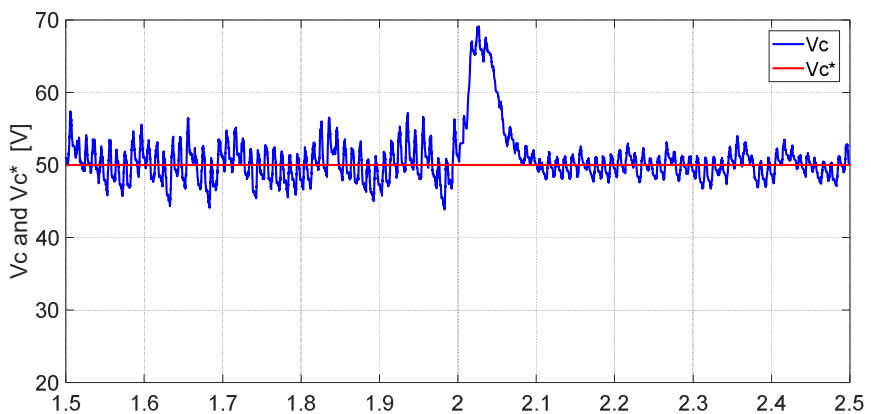

(b)

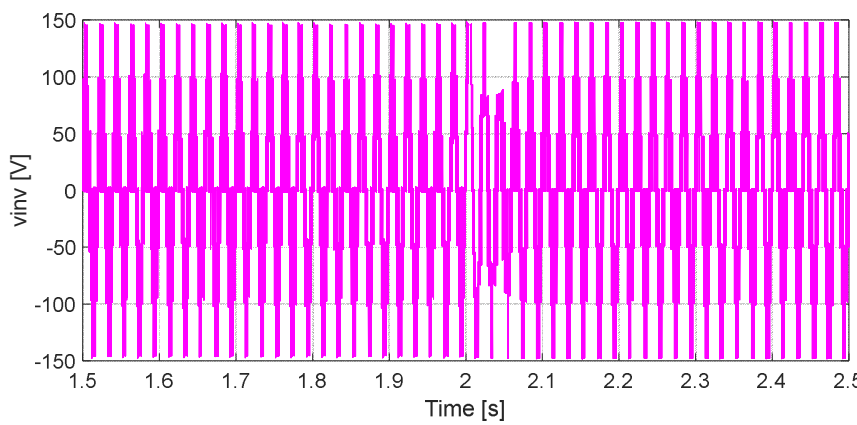

(c)

Fig. 8. Dynamic responses of AC and DC variables obtained by the proposed PI-PR based control when $R_{2}$ is disconnected suddenly at $\mathrm{t}=2 \mathrm{~s}$. (a) $i_{o}$ and $I_{o}^{*}$

(b) $V_{c}$ and $V_{c}^{*}$, (c) $v_{i n v}$.

\section{CONCLUSION}

A PI-PR based control strategy was proposed for PUC inverters. In the conventional PI-PI based control strategy, while the first PI regulates the DC capacitor voltage, the second PI regulates the AC load current. However, the second PI cannot achieve zero tracking error in the load current due to the fact that PI controllers are not able to achieve zero tracking error for the AC signals. In an attempt to reduce the tracking error by tuning PI gains leads to distortions in the load current. Hence, a PI-PR based control strategy is obtained by replacing the second PI by a PR controller. The performances of both PI-PI and PI-PR control methods have been compared. It is shown that the load current to tracks its reference in all circumstances provided that the inverter current reference is generated accurately. Computer simulations are conducted to show the steady-state and dynamic performances of both control methods.

\section{REFERENCES}

[1] A. Nabae, I. Takahashi, and H. Akagi, "A new neutral point clamped PWM inverter," IEEE Trans. Ind. Appl., vol. IA-17, no. 5, pp. 518-523, Sep./Oct. 1981.

[2] J. Rodriguez, S. Bernet, P. K. Steimer, and I. E. Lizama, "A survey on neutral-point-clamped inverters," IEEE Trans. Ind. Electron., vol. 57, no. 7, pp. 2219-2230, Jul. 2010.

[3] T. Meynard, and H. Foch, "Multi-level conversion: High voltage choppers and voltage-source inverters," in Proc. $23^{\text {rd }}$ Annu. PESC Rec., 1992, pp. 397-403.

[4] C. Feng, J. Liang, and V. G. Agelidis, "Modified phase-shifted PWM control for flying capacitor multilevel converters," IEEE Trans. Power Electron., vol. 22, no. 1, pp. 178-185, Jan. 2007.

[5] Y. Ounejjar, K. Al-Haddad, and L. A. Gregoire, "Packed U cells multilevel converter topology: theoretical study and experimental validation," IEEE Trans. Ind. Electron., vol. 58, no. 4, pp. 1294-1306, 2011 .

[6] Y. Ounejjar, K. Al-Haddad, and L. A. Dessaint, "A novel six-band hysteresis control for the packed u cells seven-level converter: Experimental validation," IEEE Trans. Ind. Electron., vol. 59, no. 10, pp. 3808-3816, Oct. 2012.

[7] H. Vahedi, K. Al-Haddad, and H. Y. Kanaan, "A new voltage balancing controller applied on 7-level PUC inverter," in Proc. 40 $0^{\text {th }}$ Annual Conference of the IEEE Industrial Electronics Society (IECON2014), 2014, pp. 5082-5087.

[8] H. Vahedi, and K. Al-Haddad, "Real-time implementation of a sevenlevel packed U-cell inverter with a low-switching-frequency voltage regulator," IEEE Trans. Power Electron., vol. 31, no. 8, pp. 5967-5973, August 2016.

[9] M. Trabelsi, S. Bayhan, K. A. Ghazi, H. Abu-Rub, and L. Ben-Brahim," Finite-control-set model predictive control for grid-connected packedU-cells multilevel inverter," IEEE Trans. Ind. Electron., vol. 63, no. 11, pp. 7286-7295, Nov. 2016.

[10] S. Xiao, M. Metry, M. Trabelsi, R. S. Balog and H. Abu-Rub, "A mode predictive control technique for utility-scale grid connected battery systems using packed U cells multilevel inverter," in Proc. of $42^{\text {nd }}$ Annual Conference of the IEEE Industrial Electronics Society (IECON2016), Florence, 2016, pp. 5953-5958.

[11] M. Trabelsi, H. Komurcugil, S. S. Refaat and H. Abu-Rub, "Model predictive control of packed U cells based transformerless single-phase dynamic voltage restorer," in Proc. $19^{\text {th }}$ IEEE International Conference on Industrial Technology (ICIT2018), Lyon, 2018, pp. 1926-1931.

[12] M. Trabelsi, S. Bayhan, S. S. Refaat, H. Abu-Rub and L. Ben-Brahim, "Multi-objective model predictive control for grid-tied 15-level packed U cells inverter," in Proc. $18^{\text {th }}$ European Conference on Power Electronics and Applications (EPE'16 ECCE Europe), Karlsruhe, 2016, pp. 1-7.

[13] H. Vahedi, P. A. Labbé, and K. Al-Haddad, "Sensor-less five-leve packed U-cell (PUC5) inverter operating in stand-alone and gridconnected modes," IEEE Trans. Ind. Informat., vol. 12, no. 1, pp. 361$370,2016$.

[14] R. Teodorescu, F. Blaabjerg, M. Liserre, and P. Loh, "Proportional resonant controllers and filters for grid-connected voltage-source converters," in Proc. Inst. Elect. Eng.-Elect. Power Appl., vol. 153, no. 5, pp. 750-762, Sept. 2006. 